\title{
REMEDIOS OFTÁLMICOS EN LA MATERIA MÉDICA DE DIOSCÓRIDES (I)
}

\author{
LÓPEZ DE LETONA C ${ }^{1}$
}

Pedacio Dioscórides fue un médico nacido en la primera mitad del siglo I D.C. en la localidad de Anazarbeo que entonces formaba parte de la península de Anatolia (Cilicia) en el Asia Menor.

Adquirió conocimientos sanitarios en Tarsos y después en la prestigiosa escuela de los asclepiades en Alejandría, pronto se desplaza a Roma; son los años del reinado del Emperador Nerón. Es médico de las legiones romanas lo que le llevó a desplazarse con ellas a Grecia, las Galias, la Península Ibérica y Siria.

Persona muy observadora recopiló todos los recursos terapéuticos utilizados por los pueblos antiguos a través de la descripción de multitud de especies vegetales, minerales o animales e incluso otras substancias, redactando un amplio tratado que se completó en el año 77 D.C. titulado en principio: Plantas y remedios medicinales, el cual estaba redactado en griego coloquial, considerado como una lengua más imperio romano.

Con el correr de los siglos se tradujo a diversos idiomas; en nuestro país no se conoció hasta 1566 , siendo el prestigioso médico Andrés Laguna el encargado de su traducción, lo hizo del griego al castellano, titulándolo: A cerca de la materia médica y de los venenos mortíferos (1).

Nos encontramos ante una obra capital dentro de la medicina que alcanzó muy amplia difusión hasta bien entrado el siglo XVIII, tal es su importancia que solo su título vino a identificarse ya con el moderno concepto de farmacología actual, conocida en sus comienzos como «Materia Médica».

Es nuestro propósito, tras una minuciosa consulta a la versión de Laguna, reeditada en forma de facsímil hace un tiempo, ofrecer en este artículo y en los siguientes las principales aportaciones referentes a remedios curativos ante determinados procesos oftalmológicos.
La obra queda dividida en seis partes de contenido algo desigual, cada una de las cuales se titulaba, tal como hemos visto en otras obras comentadas: «Libros».

El primero se subtitula: Productos aromáticos, aceites, ungüientos y los medicamentos obtenidos de los árboles y los licores, gomas y frutos que de ellos nacen.

Vaya por delante que Dioscórides ofrece primero una amplia descripción de la especia en cuestión y que el traductor amplía conocimientos por medio de una serie de anotaciones posteriores.

En el primer libro, al que antes nos referimos, se citan hasta diecinueve especies botánicas que se pueden utilizar en Oftalmología: Así la Canela (Cassia), aceite de almendras, incienso y el cedro; que clarifican la vista.

En el caso del cedro nos ofrece minuciosas noticias de cómo debe procederse ya que este árbol que ofrece una madera de excelente calidad, segrega una resina que destilada se puede instiliar en los ojos en forma de colirio: «Siendo útil para la clarificar la vista, por que quita las cicatrices y las blancas nubes que ofuscan los ojos» (2).

Otras especies sirven para los procesos inflamatorios oculares, como es el caso del hollín de incienso.

Pero donde presenta más noticias de interés es en lo referente al ébano que también clarifica la vista y «reprime las antiguas destilaciones» (lagrimeo), así como «deseca las postillas que suelen engendrarse en los ojos».

Se debe raspar una rama de esta madera que posteriormente se mezcla con vino de Chios (localidad griega), instilándose la solución obtenida.

También el betún llamado Naptha «Vale contra las cataratas y contra las blanquecinas nubes que en los ojos se engendran». Del mismo modo la mirra es útil para sanar las úlceras oculares.

1 IOBA. Valladolid. España.

E-mail: berta@ioba.med.uva.es 
Otras productos poseen cierto componente de brujería como es el caso de la flor de granada o de las avellanas.

De las primeras afirma que si se comen tres de ellas «por pequeñas que sean», se quedará libre del mal de ojo al menos durante un año.

Las cáscaras de avellana por su parte si se quemasen y sus cenizas se mezclasen con aceite $« Y$ se aplicasen en la mollera de los niños que tienen los ojos garzos (azulados) les hará cambiar las niñetas (pupilas) a negras».

No cabe duda que esto último resulta cuanto menos sorprendente.

Otros remedios pueden servir como componentes de algunas medicinas de aplicación oftalmológica, así las rosas que una vez machacadas se «guardan para los medicamentos que se suelen instilar en los ojos».

Caso semejante ocurre con el licor que destila la acacia.

Existe otra especia vegetal que nos interesa por su fuerte presencia en nuestro país: el olivo. De él nuestro autor describe dos aplicaciones diferentes:
Por un lado la del árbol en sus variantes: salvaje y doméstica, pero también la llamada goma del olivo etiópico cuya resina («Goma») instilada vale «Contra la flaqueza de la vista y corrige las señales y nubes que perturban la vista».

Hay otros productos, entre ellos el terebinto el cual: «Aplicado restablece las pestañas y cejas caducas».

Del mismo modo el arrayan (Planta especialmente frecuente en Andalucía), «Cocida su simiente con vino se aplica útilmente contra las enfermedades de los ojos mezclado con flor de harina y contra las fístulas de los ojos».

\section{NOTAS}

1. Andrés Laguna. Pedacio Dioscorides Anazarbeo: A cerca de la materia médica y de los venenos mortíferos. Edición de 1566. Biblioteca de clásicos de la medicina y de la farmacia española. Madrid. Ediciones doce calles. 1999.

2. Siempre que entrecomillamos nos referimos a lo traducido por Laguna partiendo del texto de Dioscórides. 